\title{
Microstructure in the Semi-solid State and Mechanical Properties of AZ80 Magnesium Alloy Reheated from the As-cast and Extruded States
}

Wenyong JIANG, Tian CHEN ${ }^{\dagger}$, Liping WANG, Yicheng FENG, Yan ZHU, Kaifeng WANG, Jiapeng LUO and Shouwei ZHANG

College of Materials Science and Engineering, Harbin University of Science and Technology, Harbin 150040, China

[Manuscript received 17 October 2012, in revised form 5 March 2013]

(C) The Chinese Society for Metals and Springer-Verlag Berlin Heidelberg

The multi-axial forging (MAF) process was introduced into the strain induced metal activation (SIMA) process to replace conventional forging. Microstructure evolution of MAF formed AZ80 magnesium alloy during partial remelting was investigated. Furthermore, the tensile mechanical properties for AZ80 magnesium alloy thixoextruded from the starting materials treated by MAF were determined. For comparison, as-cast AZ80 magnesium alloy was also thixoextruded. The results show that the SIMA route produced ideal, fine semi-solid microstructure, in which almost completely spheroidal primary solid grains had a little amount of entrapped liquid. The microstructure of the as-cast alloy in the semi-solid state is less spheroidized compared with the MAF alloy under the similar isothermal holding conditions. With prolonged holding time, the size of the solid grain increases and the degree of spheroidization is improved in the MAF formed alloys. However, the solid grain size of the as-cast alloys decreases initially, and then increases with further increasing temperature. The tensile mechanical properties for AZ80 magnesium alloy thixoextruded from the starting material produced by MAF are better than those of AZ80 magnesium alloy thixoextruded from the starting material produced by casting. The ultimate tensile strength, yield strength and elongation of the alloy thixoextruded from the starting material produced by MAF are $314 \mathrm{MPa}, 238 \mathrm{MPa}$ and $14 \%$, respectively.

KEY WORDS: Magnesium alloy; Microstructure; Mechanical properties; Partial remelting

\section{Introduction}

Magnesium alloys, which have characteristics of low density, high specific strength and good damping capacity, good manufacturing and recycling, have wide applications in electronics, automotive and aerospace industries ${ }^{[1-6]}$. Compared with the conventional casting and forging techniques, semi-solid processing has many advantages, such as reduction of macro-segregation, less entrapped air, better mechanical properties and longer die life $\mathrm{e}^{[7]}$. The key issue of semi-solid processing is the preparation of non-dendritic structure ${ }^{[8,9]}$. There are various routes

\footnotetext{
† Corresponding author. Prof., Ph.D.; Tel: +86 18304639120; E-mail address: cq60suo@163.com (Tian CHEN)
}

to obtain the non-dendrite structure, which are summarised by Ref. [10]. Among them, strain induced melt activation (SIMA) is an effective technology with significant commercial advantages of simplicity and low equipment cost in the fabrication process. The SIMA process involves working, such as rolling, forging and extrusion, above the recrystallisation temperature followed by reheating to the semi-solid state.

Several researchers have reported on microstructure evolution and thixoforming of magnesium alloys in the semi-solid state ${ }^{[11-14]}$. Zhao et al. ${ }^{[11]}$ have reported the microstructure evolution of AM60B magnesium alloy prepared by the SIMA route. They found that the pre-deformation refined the semi-solid microstructure. With increasing the equivalent strain, coarse grains were refined, which was favorable for formation of spheroidal grains during partial remelting. 
Chen et al. ${ }^{[12]}$ integrated squeeze casting-solid extrusion with partial remelting to innovate a new method to produce semi-solid billets. The innovative process reduced processing steps and enables precise forming of complex components. The process has been shown to produce ideal, fine semi-solid structures, in which completely globular primary phase particles were essentially free of entrapped liquid. The ideal and fine semi-solid structures were very suitable for thixoforming. Su et al. ${ }^{[13]}$ have reported the effects of semi-solid isothermal process parameters on microstructure of Mg-Gd alloy prepared by the SIMA process. The results indicated that the ideal semi-solid slurry was obtained at $630{ }^{\circ} \mathrm{C}$ for $30 \mathrm{~min}$. Luo et al. ${ }^{[14]}$ have reported the effects of isothermal temperature and isothermal holding time on the semi-solid microstructures of AZ91D alloys prepared by the SIMA process. They found that increasing the isothermal temperature resulted in grain coarsening, improvement in the degree of spheroidization and increase in the amount of liquid phase. Moreover, prolonged isothermal holding time also resulted in grain coarsening and increased in the amount of liquid phase.

In the SIMA process, conventional forging was used to pre-deform as-cast magnesium alloy. However, due to limited the amount of deformation, the microstructure treated by conventional forging was inhomogeneous, which exerted disadvantage influences on the formation of spheroidal grains and mechanical properties of final components ${ }^{[15-21]}$. To overcome the disadvantages mentioned above, the MAF process was introduced into a SIMA process to replace conventional forging. Multi-axial forging (MAF) seems to be especially attractive for its potential for scaling up of relatively large samples that can be suitable for industrial applications.

The aim of this paper is to disclosure the microstructure evolutions during partial remelting of AZ80 magnesium alloy treated by casting and MAF. Furthermore, the mechanical properties of components thixoextruded from the starting materials treated by casting and MAF are also investigated.

\section{Experimental}

The feedstock material used in the present study was an as-cast AZ80 magnesium alloy. The composition (wt.\%) of as-cast AZ80 alloy was Al 8.5, Zn 0.5, Mn 0.12, Fe 0.003, Cu 0.02, Ni 0.001 and $\mathrm{Mg}$ balance. AZ80 magnesium alloy was melted in an electric resistance furnace under the protection of $\mathrm{SF}_{6}$ and $\mathrm{CO}_{2}$ mixed gas with the volume ratio of $1: 100$. The metal was isothermally kept at $760{ }^{\circ} \mathrm{C}$ for 25 min to ensure it was completely melted, and then poured into a steel model. The solidus and the liquids temperatures of the as-cast AZ80 magnesium alloy were obtained as $514{ }^{\circ} \mathrm{C}$ and $615{ }^{\circ} \mathrm{C}$ from a differential scanning calorimeter (DSC) experiment at $6{ }^{\circ} \mathrm{C} / \mathrm{min}$. Theoretical solid fractions of as-cast AZ80 alloy were calculated according to the Scheil equation ${ }^{[20]}$ :

$$
f_{\mathrm{s}}=1-\left(\frac{T_{\mathrm{m}}-T}{T_{\mathrm{m}}-T_{\mathrm{L}}}\right)^{\frac{1}{k_{0}-1}}
$$

where $T_{\mathrm{m}}$ is the melting temperature of pure metal, $T_{\mathrm{L}}$ is the liquids temperature of the alloy and $k_{0}$ is the equilibrium distribution coefficient. In this study, $T_{\mathrm{m}}$ and $k_{0}$ are taken as $650{ }^{\circ} \mathrm{C}$ and 0.36 , respectively.

Fig. 1 shows the photograph of the as-cast AZ80 alloy. Some of the as-cast AZ80 magnesium alloys bar were cutted into feedstocks with dimensions of 80 $\mathrm{mm} \times 80 \mathrm{~mm} \times 160 \mathrm{~mm}$ for MAF, and loading direction was turned by $90^{\circ}$ from pass to pass with a 800 ton hydraulic press. The billets were preheated at $300{ }^{\circ} \mathrm{C}$ for $80 \mathrm{~min}$ and then formed through the MAF die preheated to $300{ }^{\circ} \mathrm{C}$, at a speed of $1 \mathrm{~mm} / \mathrm{s}$. Both the die and billets were lubricated with Molybdenum disulphide $\left(\mathrm{MoS}_{2}\right)$. MAF was performed about at $300{ }^{\circ} \mathrm{C}$. The equivalent strain according to the following equation ${ }^{[22,23]}$ :

$$
\varepsilon=n\left|\ln \left(h_{0} / h\right)\right|
$$

where $h_{0}$ and $h$ are the initial height and final height of feedstocks; $n$ is the number of MAF passes.

The equivalent strain is approximately equal to 2.1 after three-pass MAF with $50 \%$ reduction in height per pass. Fig. 2 shows the photograph of the threepass MAF formed AZ80 magnesium alloy.

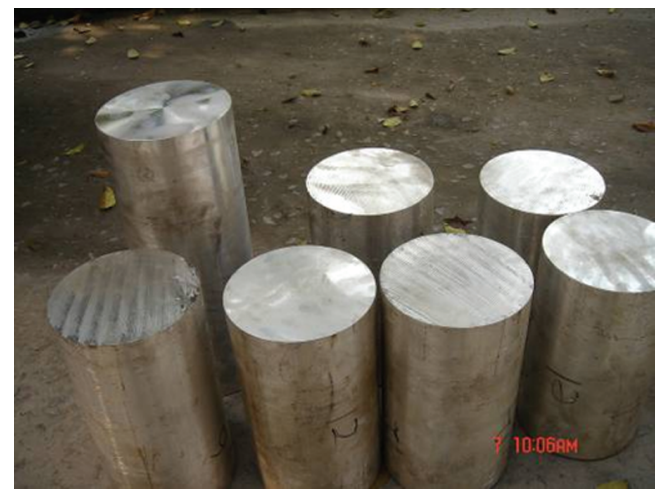

Fig. 1 Photograph of as-cast AZ80 ingot

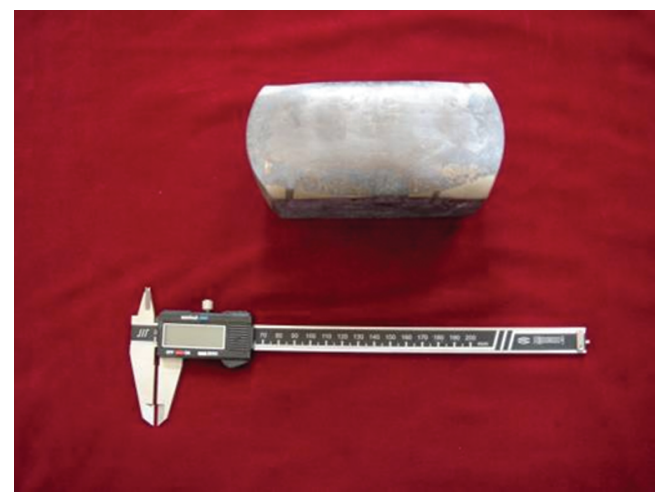

Fig. 2 Photograph of the three-pass MAF formed AZ80 ingot 


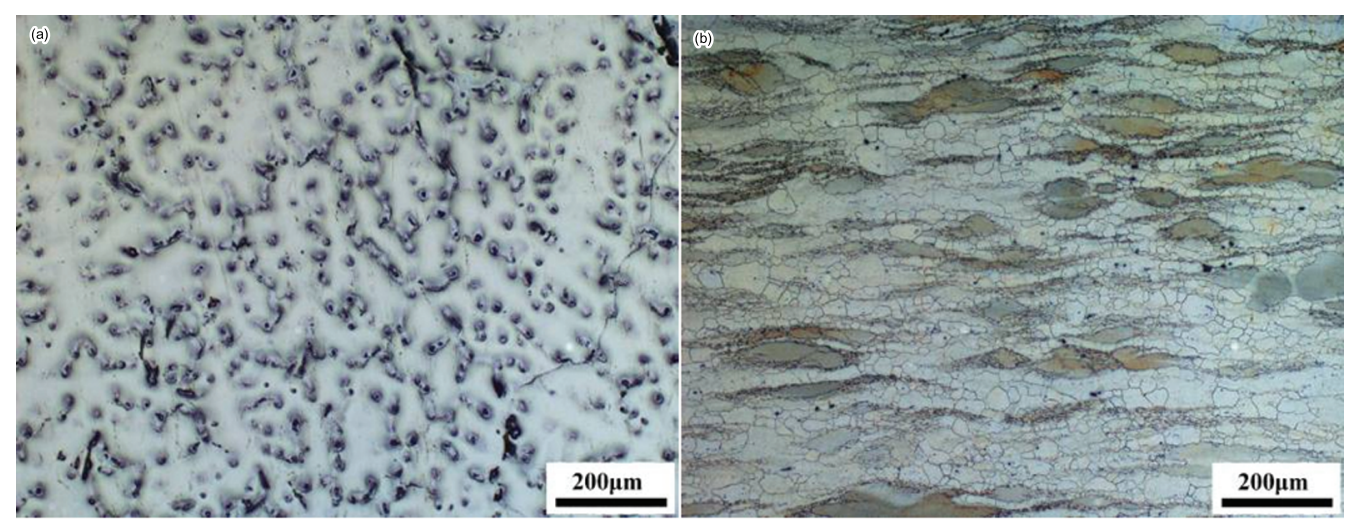

Fig. 3 Microstructure of the as-cast (a) and three-pass MAF formed (b) AZ80 magnesium alloys

Both MAF and the as-cast formed billets were machined into small cylindrical samples with a diameter of $8 \mathrm{~mm}$ and a height of $12 \mathrm{~mm}$ for partial remelting experiments. The samples were heated into the semisolid state in a vertical infrared tube furnace under a protective gas flow (Ar atmosphere), isothermally held. When the holding time was reached, the sample was removed from the furnace and was quenched in cold water. A thermocouple placed in a hole of $1 \mathrm{~mm}$ diameter and $5 \mathrm{~mm}$ depth in the centre of the sample ensured accurate temperature measurement and feedback control. During isothermal holding, the fluctuation range of average temperature was controlled at $\pm 3{ }^{\circ} \mathrm{C}$.

Before the thixoextrusion, slugs of $80 \mathrm{~mm}$ diameter and $60 \mathrm{~mm}$ length were machined from the MAF formed and the as-cast billets. Thixoextrusion was carried out on an oil hydraulic press. The die used for thixoextrusion was heated to $350{ }^{\circ} \mathrm{C}$. Argon was used as a protective gas to reduce oxidation. The heating process was monitored by using a K-type thermocouple embedded in the billets. After the required temperature was reached, the thermocouple was removed and the heated slug was placed into the die for thixoextrusion. The exerted pressure on the slugs was $400 \mathrm{MPa}$ and dwell time was $30 \mathrm{~s}$.

Metallographic specimens were ground with $\mathrm{SiC}$ paper of different fineness and polished with $1 \mu \mathrm{m}$ diamond paste. The MAF formed samples were etched in a solution of $100 \mathrm{~mL}$ ethanol, $6 \mathrm{~g}$ picric acid, $5 \mathrm{~mL}$ acetic acid and $10 \mathrm{~mL}$ water. As-cast and partially remelted samples were etched in a solution of $4 \%$ $\mathrm{HNO}_{3}$ aqueous solution. Tensile samples were tested using an Instron 5569 testing machine at a cross head speed of $1 \mathrm{~mm} / \mathrm{min}$. The tensile samples shaped dog bone had a gauge length of $15 \mathrm{~mm}$ and a thickness of $2 \mathrm{~mm}$. Tensile curves were analyzed to assess the ultimate tensile strength, yield strength and elongation to failure. At least five measurements were tested in each condition. Mean grain size (d) and shape factor $(F)$ of solid particles were calculated in each case according to Eq. (3) and Eq. (4) ${ }^{[24-27]}$,

$$
\begin{gathered}
d=\frac{\sum_{N=1}^{N} \sqrt{4 A / \pi}}{N} \\
F=\frac{\sum_{N=1}^{N} \frac{4 \pi A}{P^{2}}}{N}
\end{gathered}
$$

where $A$ and $P$ are area and perimeter of the solid grains, respectively, and $N$ is the number of the solid grains. For each sample, measurements were taken from the whole sectioned area with 200-300 solid grains per sample.

\section{Results and Discussion}

\subsection{Microstructure formed by casting and MAF}

Fig. 3 shows microstructures of the as-cast AZ80 magnesium alloys and three-pass MAF formed AZ80 magnesium alloys. As-cast AZ80 magnesium alloy consisted of $\alpha-\mathrm{Mg}$ matrix and $\beta-\mathrm{Mg}_{17} \mathrm{Al}_{12}$ phase (Fig. 3(a)). The presence of $\beta-\mathrm{Mg}_{17} \mathrm{Al}_{12}$ phase mainly distributed at the grain boundaries. The formation of $\beta-\mathrm{Mg}_{17} \mathrm{Al}_{12}$ phase was attributed to non-equilibrium solidification created by the fast cooling rate of conventional casting processes. After three-pass MAF, a heterogeneous grained structure was obtained in Fig. 3(b). The appearance of this 'bimodal' distribution of the grain size and the fine grains at original coarse grain boundaries indicate that dynamic recrystallization occurred. The driving force for dynamic recrystallization was associated with the excess energy stored in the crystal as a result of MAF. This dynamic recrystallization mechanism can explain the "bimodal" microstructure during the grain-refinement process. The microstructural features of the threepass MAF formed AZ80 magnesium alloys, on the other hand, was obviously elongated eutectic constituents in the deformation direction. However, the amount of $\mathrm{Mg}_{17} \mathrm{Al}_{12}$ phase was reduced but not eliminated after MAF. The eutectic constituents, such as 


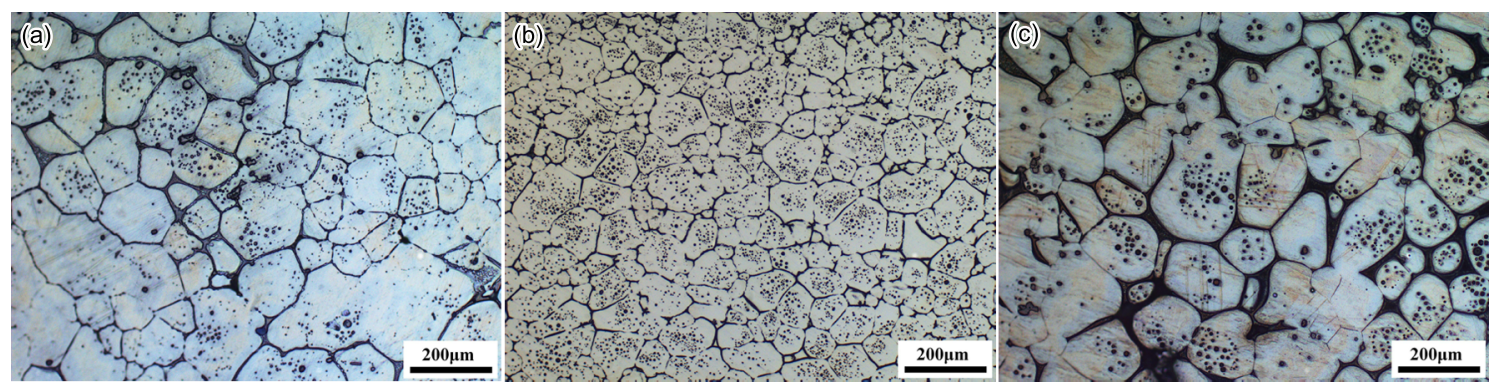

Fig. 4 Microstructures of the as-cast formed AZ80 magnesium alloy partially remelted at $550{ }^{\circ} \mathrm{C}(\mathrm{a}), 570{ }^{\circ} \mathrm{C}(\mathrm{b})$, $580{ }^{\circ} \mathrm{C}$ (c) for $10 \mathrm{~min}$ isothermal holding

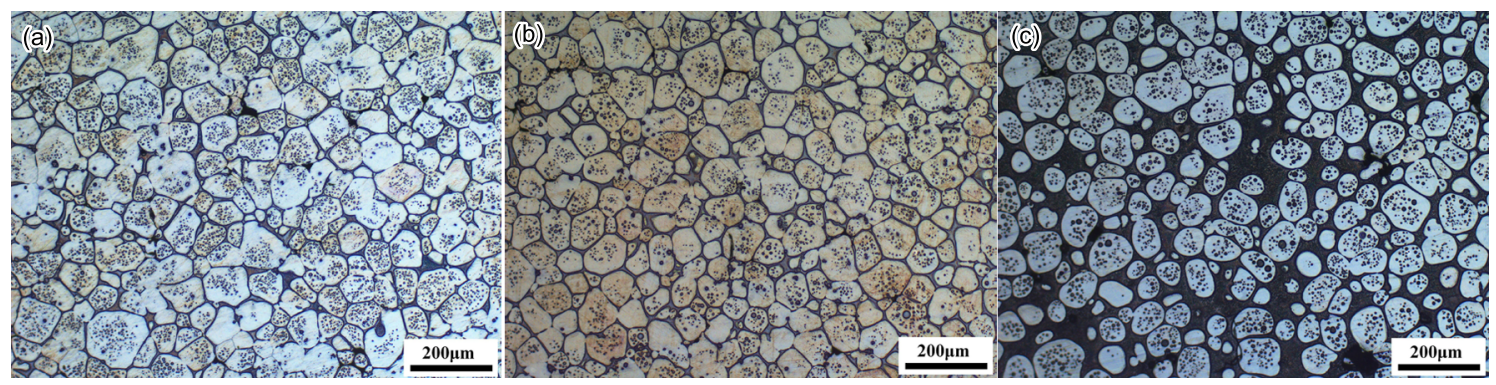

Fig. 5 Microstructures of MAF formed AZ80 magnesium alloy partially remelted at $550{ }^{\circ} \mathrm{C}$ (a), $570{ }^{\circ} \mathrm{C}$ (b), $580{ }^{\circ} \mathrm{C}(\mathrm{c})$ for $10 \mathrm{~min}$ isothermal holding

$\mathrm{Mg}_{17} \mathrm{Al}_{12}$, were often produced in the area of high level of aluminium, got partially dissolved during temperature processing. However, the time was too short to ensure complete homogenization ${ }^{[28-31]}$.

\subsection{Effect of isothermal temperature on the mi- crostructure of as-cast and MAF formed AZ80 magnesium alloy during partial remelting}

Fig. 4 shows microstructure of the as-cast formed AZ80 magnesium alloy partially remelted at different temperatures for $10 \mathrm{~min}$ isothermal holding. As shown in Fig. 4(a), after holding at $550{ }^{\circ} \mathrm{C}$ for $10 \mathrm{~min}$, the microstructure consisted of coarse grains and some of them have not been penetrated by liquid. Increasing isothermal temperature to $570{ }^{\circ} \mathrm{C}$ (Fig. 4(b)), the interconnected solid grains were separated into isolated solid grains due to liquid penetration. When isothermal temperature increased to $580{ }^{\circ} \mathrm{C}$ (Fig. 4(c)), the microstructure consisted of coarse grains with irregular shape.

The microstructures of the MAF formed AZ80 alloys after partial remelting at different temperatures for $10 \mathrm{~min}$ isothermal holding are shown in Fig. 5. With increase of temperature up to $550{ }^{\circ} \mathrm{C}$ for $10 \mathrm{~min}$ holding, deformed microstructure was replaced by fine and spheroidal solid grains (Fig. 5(a)). With increasing isothermal temperature, liquid fraction increased and the thickness of the grain boundary liquid film were thicker (Fig. 5(b) and Fig. 5(c)). Comparing Fig. 4(c) with Fig. 5(c), it is found that the process
(MAF plus partial remelting) has been shown to produce ideal, fine semi-solid microstructure, in which completely spheroidal grains have a little amount of entrapped liquid. It can also be found that the liquid formation rate of MAF formed alloy was higher than that of as-cast alloy.

Fig. 6 shows the grain size and shape factor for the as-cast alloy and the MAF formed alloy during partial remelting. As shown in Fig. 6(a), when the temperature increased from $550{ }^{\circ} \mathrm{C}$ to $580{ }^{\circ} \mathrm{C}$, the solid grain size of the as-cast alloys decreased initially, and then increased with further increasing temperature. However, the grain size for the MAF formed alloy exhibited a tendency where the increase of the isothermal temperature caused decrease in the grain size. Grain coarsening in the semi-solid alloys was controlled by the grain coalescence and Ostwald ripening. Once liquid was formed, the grain coalescence and Ostwald ripening operated simultaneously and independently. In the as-cast alloy, the starting microstructure was coarse dendritic microstructures. With increasing temperature from $550{ }^{\circ} \mathrm{C}$ to $570{ }^{\circ} \mathrm{C}$, the coarse dendrites broke up due to the dissolution of the last solidified phase with a low melting temperature. Then the dendrites were separated into individual grains as the liquid phase formed between the dendrites. Therefore, the solid grain size of the as-cast alloys decreased with increasing temperature. With increasing temperature from $570{ }^{\circ} \mathrm{C}$ to $580{ }^{\circ} \mathrm{C}$, individual grains coarsened.

Because these individual grains had relatively 

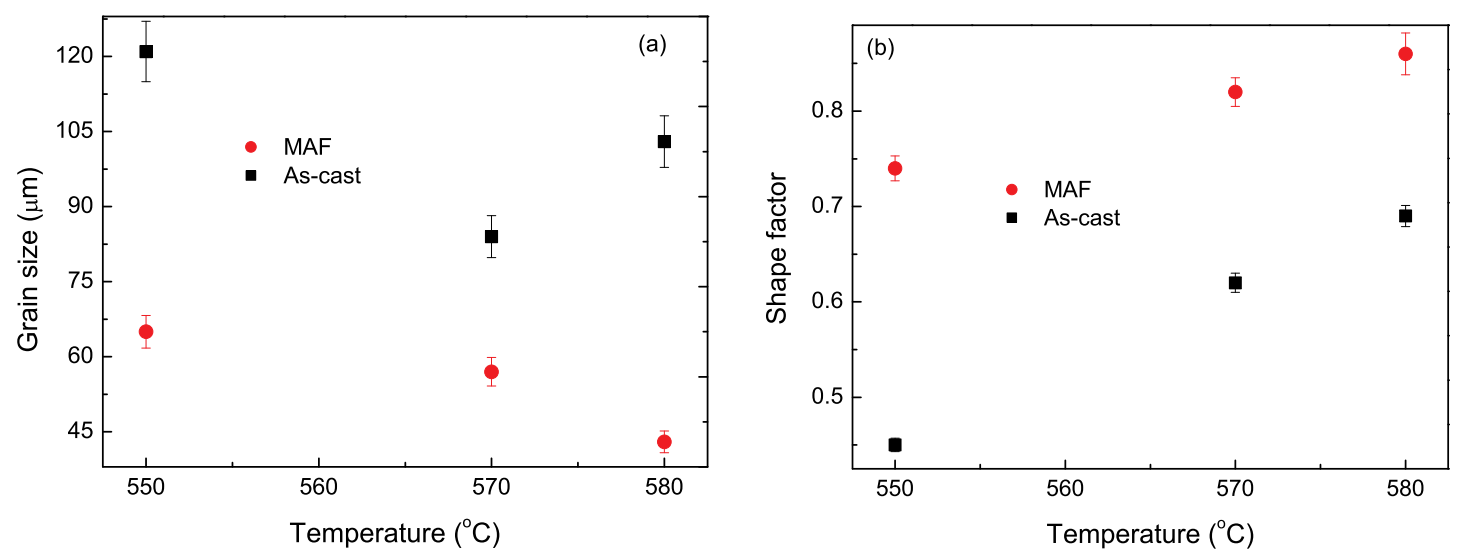

Fig. 6 Grain size (a) and shape factor (b) for the as-cast and MAF alloys during the partial remelting at different reheating temperatures

coarse size and irregular shape, coalescence played a significant role in grain coarsening. However, in the MAF formed alloy, the starting microstructure was fine and equiaxed recrystallised grains. During partial remelting, solid grains were uniformly surrounded by liquid. Grain coarsening was mainly controlled by Ostwald ripening. On the one hand, higher temperature resulted for faster diffusion rate. On the other hand, the thickness of the liquid film surrounding the solid grains was thicker at higher temperature, which resulted in the increase of diffusion distance. This was a counter effect on the grain coarsening in the MAF alloy. Therefore, the grain size of MAF alloy continuously decreased with reheating temperature. In general, the phenomena put forward for variation of the grain size of the as-cast alloys with temperature was not applicable for MAF alloys due to the obvious difference of their starting microstructures. As shown in Fig. 6(b), both the as-cast alloy and the MAF formed alloy shows a similar trend of the shape factor. Raising temperature was helpful for the improvement of the degree of spheroidization. However, shape factor of the MAF formed alloy ranges from 0.74 to 0.86 , which is closer to 1 at $580{ }^{\circ} \mathrm{C}$. However, shape factor of the as-cast alloy increase from 0.45 to 0.69 when the temperature increased from $550{ }^{\circ} \mathrm{C}$ to $580{ }^{\circ} \mathrm{C}$.

3.3 Effect of isothermal holding time on the microstructure of as-cast and MAF formed AZ80 magnesium alloy during partial remelting

Fig. 7 and Fig. 8 show the microstructures of the as-cast AZ80 magnesium alloy and MAF formed AZ80 magnesium alloy partial remelted at $570{ }^{\circ} \mathrm{C}$ for different isothermal holding times, respectively. When the isothermal holding time was only $10 \mathrm{~min}$, the solid grains were not fully penetrated by liquid film with blocky structure due to low liquid fraction (Fig. 4(b)). However, when the isothermal holding time was extended to $20 \mathrm{~min}$, the blocky structure gradually disintegrated into individual polygonal solid grains and the amount of liquid increased due to liquid penetration (Fig. 7(a)). With further increasing isothermal holding time, solid grains had undergone coarsening by coalescence, but the amount of liquid was not further increased. The variation of the grain size with isothermal holding time obey the formula, $D_{\mathrm{t}}^{3}-D_{0}^{3}=K t$ (where $D_{\mathrm{t}}$ is the average grain size at time $t, D_{0}$ is the initial grain sizes and $K$ is the coarsening rate constant).

Compared to the microstructure of the as-cast alloy, the solid grain size of MAF formed AZ80 magnesium alloy obviously decreased and the shape became more spheroidal. Moreover, the amount of liquid in the MAF formed alloy was higher than that in the as-cast alloy (Fig. 7(a) and Fig. 8(a)). It is obviously observed that the segregation of liquid was seriously and the grain coarsening was enhanced with further increasing isothermal holding time (Fig. 8(b)).

In general, the theoretical volume fraction of liquid was dependent on the chemical composition and the temperature (Fig. 4 and Fig. 5). As expected, higher temperature resulted in greater amount of volume fraction. However, besides the chemical composition and the temperature, isothermal holding time and the deformation amount of MAF also exerted significant influences on the practicable volume fraction of liquid. The formation of liquid fraction was a process of atom diffusion. Isothermal holding time was too short to reach the equilibrium condition, as shown in Fig. 7(a) and Fig. 8(a). Before the equilibrium condition reached, the prolonged isothermal holding time was favourable for the formation of liquid. Compared Fig. 4(c) with Fig. 5(c) indicated that MAF promoted the formation of liquid. The MAF process resulted in the distortion of crystal lattices and the accumulation of dislocations in the deformed grains, which led to accumulation of distortion energy in the material. The more the numbers of MAF passes, the greater the overall grain boundary and sub-grain boundary area. The state of MAF formed material was thermodynamic unstable. When the temperature increased 


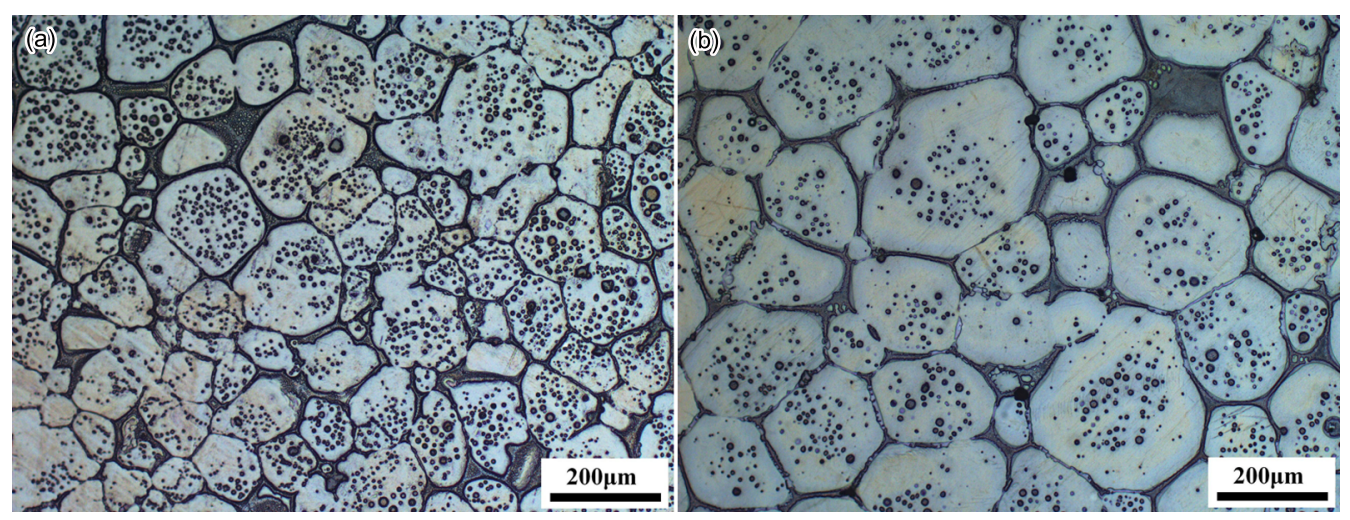

Fig. 7 Optical micrographs of the as-cast AZ80 magnesium alloy isothermally held at $570{ }^{\circ} \mathrm{C}$ for 20 min (a) and $40 \min (\mathrm{b})$

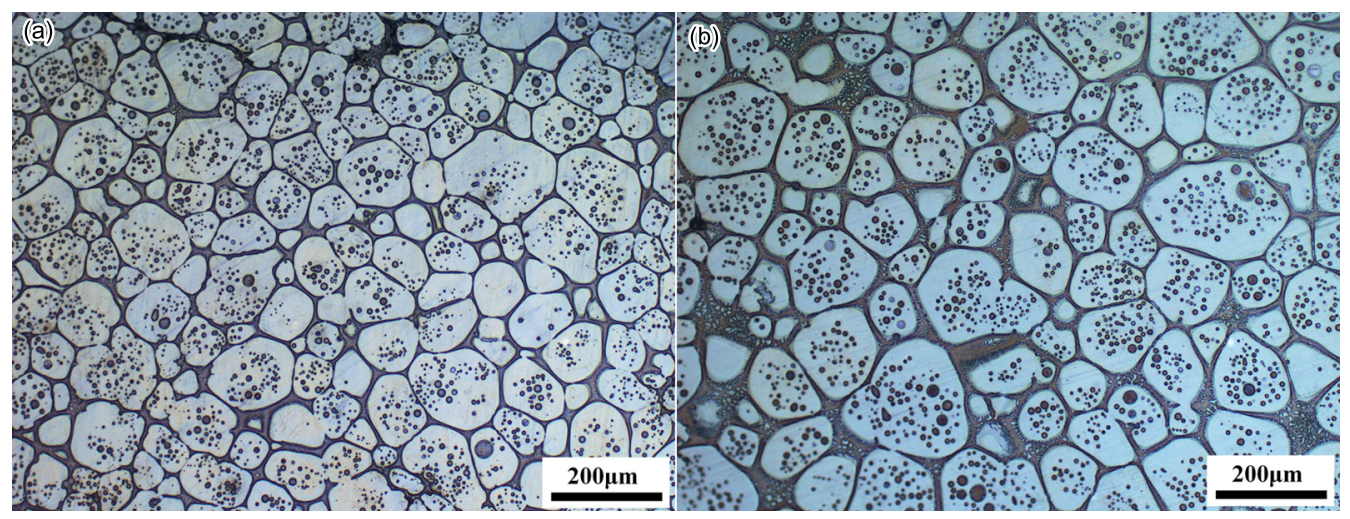

Fig. 8 Optical micrographs of MAF formed AZ80 magnesium alloy isothermally held at $570{ }^{\circ} \mathrm{C}$ for 20 min (a) and $40 \mathrm{~min}(\mathrm{~b})$

to above solidus, the materials treated by MAF had much solid-liquid interfacial energy than that only treated by casting. With increasing solid-liquid interfacial energy, diffusion rate increased, which in turn enhanced the rate of liquid formation. Therefore, compared with as-cast microstructure, it appeared that the microstructure treated by MAF had a higher amount of volume fraction at the same thermodynamic parameter.

\subsection{Intragrangular liquid droplets during partial remelting}

Intragrangular liquid droplets presented in each case during partial remelting. Fig. 9 shows the liquid droplets after holding for $90 \mathrm{~min}$ in the MAF alloy. To further determine the component of liquid droplets in Fig. 9, SEM and EDS analyses of MAF formed AZ80 magnesium alloy after $90 \mathrm{~min}$ holding were carried out, as shown in Fig. 10. EDS analysis indicates that the liquid droplets (A point) mainly consisted of $\mathrm{Mg}$ and $\mathrm{Al}$ and the $\mathrm{Mg} / \mathrm{Al}$ ratio was $80.20 / 19.80$. The $\mathrm{Mg} / \mathrm{Al}$ ratio of liquid droplets was close to the grain boundary liquid film (B point) with $\mathrm{Mg} / \mathrm{Al}$ ratio of $78.93 / 21.07$. It indicated that the chemical composi-

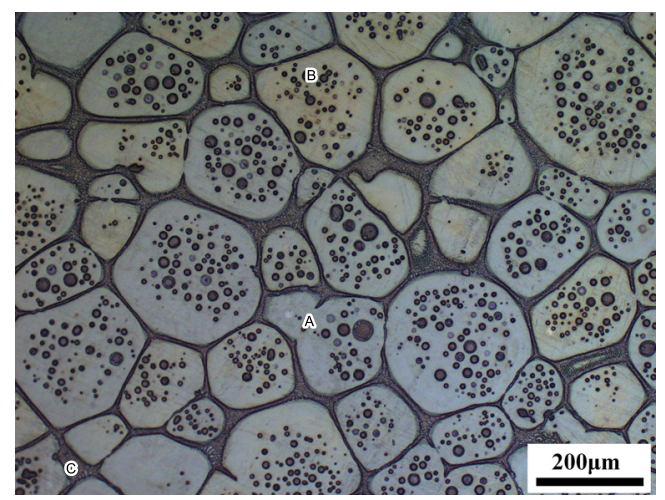

Fig. 9 Microstructures of MAF formed alloy partially remelted at $570{ }^{\circ} \mathrm{C}$ for $90 \mathrm{~min}$ isothermal holding (A is labelled as the formation of entrapped liquid resulted from coalescence between two solid grains; $\mathrm{B}$ is labelled as coalescence between two intragranular liquid droplets; $\mathrm{C}$ is labelled as migration of intragranular liquid droplet to grain boundary liquid film)

tion located in liquid droplets was almost the same as that located in grain boundary liquid film. The $\mathrm{Mg} / \mathrm{Al}$ ratio of $\alpha$-Mg matrix (C point) was 99.06/0.94. 


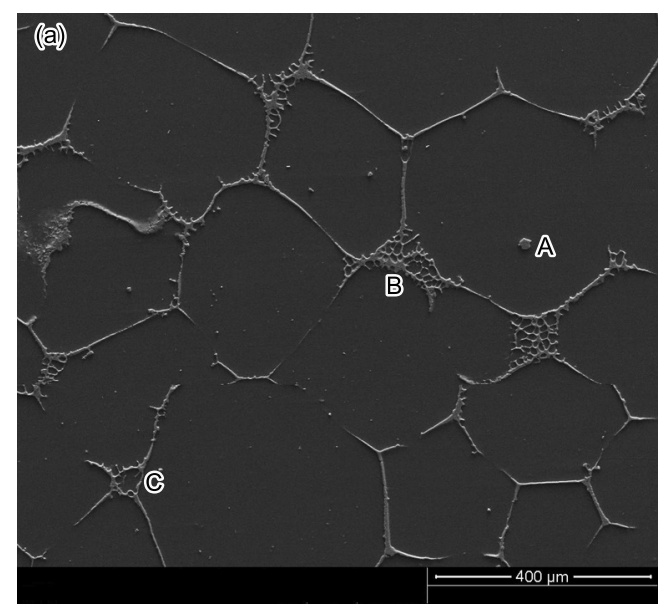

\begin{tabular}{cccc}
\hline Site & \multicolumn{3}{c}{ Element content (at.\%) } \\
\cline { 2 - 4 } & $\mathrm{Mg}$ & $\mathrm{Al}$ & Totals \\
\hline Point A & 80.20 & 19.80 & 100 \\
Point B & 78.93 & 21.07 & 100 \\
Point C & 99.06 & 0.94 & 100 \\
\hline
\end{tabular}

(b)

Fig. 10 SEM image of MAF formed AZ80 magnesium alloy after holding for $90 \mathrm{~min}$ at $570{ }^{\circ} \mathrm{C}$ (a) and EDS analysis results of points A, B, C in Fig. 10(a) (b)

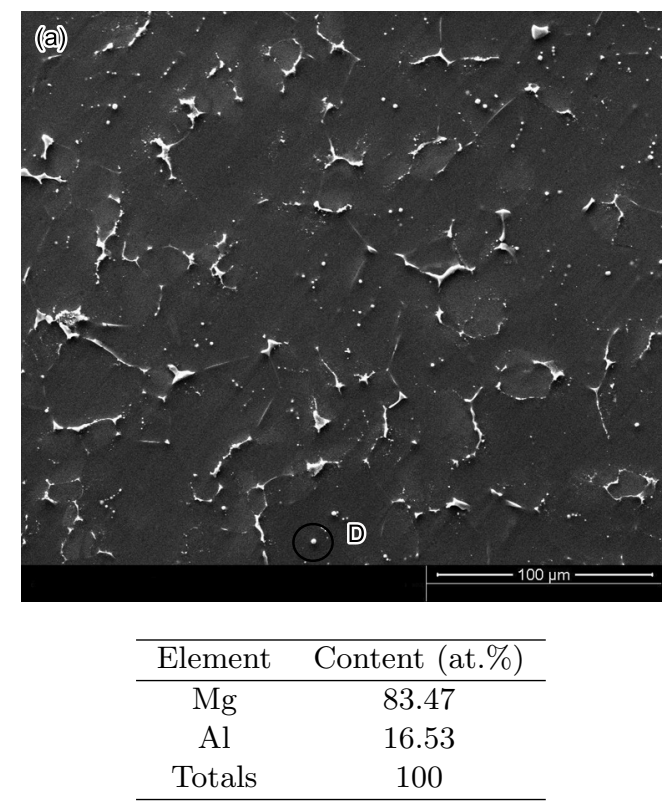

(b)

Fig. 11 SEM image of MAF formed AZ80 magnesium alloy (a) and EDS analysis of D point in Fig. 11(a) and (b)

Fig. 11 shows the SEM image and EDS analysis of MAF formed AZ80 magnesium alloy. As shown in Fig. 11(a), the chemical segregation (D point) obviously occurred interior of the grain. The chemical composition in $\mathrm{D}$ point mainly consisted of $\mathrm{Mg}$ and $\mathrm{Al}$ and the $\mathrm{Mg} / \mathrm{Al}$ ratio was $83.47 / 16.53$. The evidence in Fig. 11 confirmed that the intragranular liquid droplets mainly originated from the internal inhomogeneity of the primary solid owing to the chemical segregation, which was typical for the magnesium alloys. During isothermal holding, intermetallic of $\mathrm{Mg}_{17} \mathrm{Al}_{12}$ with low melting point located within the grains formated so-called "entrapped liquid". In order to reduce the interface energy between the solid phase and liquid phase, the grains tended to aggregation in certain directions whose grain boundaries' energy is relatively low. Some bound grains, which were not penetrated by liquid for the simple reason that $\gamma_{\mathrm{gb}}<2 \gamma_{\mathrm{sl}}$, where $\gamma$ was the surface energy and subscripts gb and sl standed for solid/solid and solid/liquid interface, respectively ${ }^{[32-39]}$. Under this condition, it was inevitable that contacted solid grains tend to coalescence and form agglomerates. Coalescence resulted in the formation of entrapped liquid, as shown in point A (Fig. 9). Some contiguous intragranular liquid droplets gradually merged into some larger ones, with increasing isothermal holding time, to minimize the solid-liquid interface energy inside the grains (B point in Fig. 9). Furthermore, some liquid droplets inside the grains also migrated to the grain boundary liquid film by diffusion through solid grain (C point in Fig. 9). It was also interesting to observe that the intragranular liquid droplets became spheroidal in appearance with further increasing holding time to minimize solid-liquid interfacial energy.

\subsection{Mechanical properties of thixoextruded AZ80 magnesium alloy components}

Fig. 12 shows a photograph of five successfully thixoextruded demonstrator components. The components of starting materials were AZ80 magnesium alloy produced by casting and MAF. It revealed that no problem was experienced in filling the wall sections in the as-cast alloys and the MAF alloys. However, the mechanical properties were remarkably different. The values of the ultimate tensile strength, yield strength and elongation to fracture, plotted as a function of isothermal holding time at $570{ }^{\circ} \mathrm{C}$ are

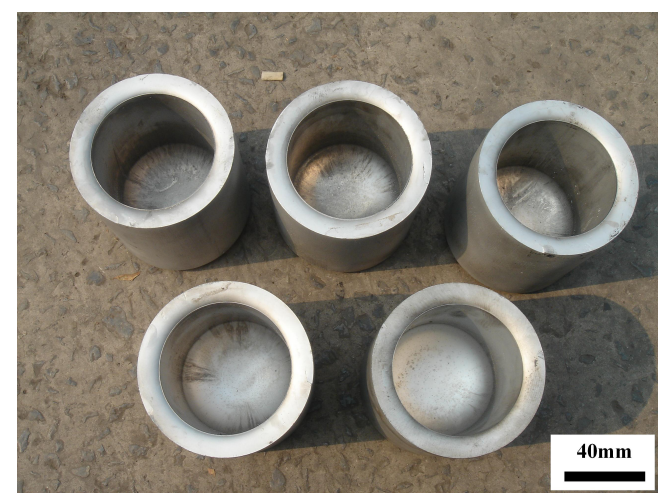

Fig. 12 Photograph of five successfully thixoextruded demonstrator components 

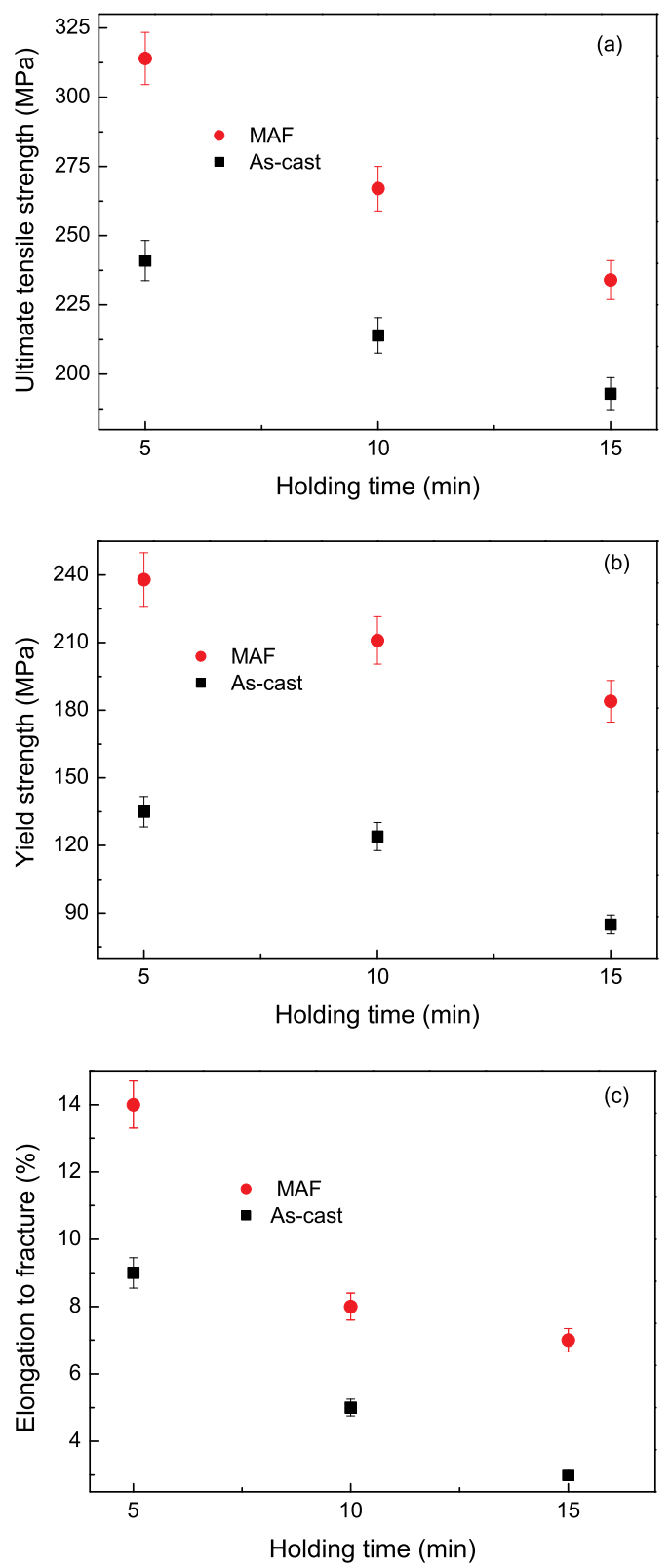

Fig. 13 Tensile mechanical properties of the thixoextruded as-cast alloy and MAF alloy plotted as a function of holding time: (a) ultimate tensile strength; (b) yield strength; (c) elongation

showed in Fig. 13. The mechanical properties of thixoformed components exhibited a decreased tendency. However, the mechanical properties of the thixoextruded AZ80 alloys, which were produced by the MAF showed a considerable improvement over the as-cast alloy. When the MAF formed AZ80 alloys were thixoextruded at $570{ }^{\circ} \mathrm{C}$ for $5 \mathrm{~min}$, the ultimate tensile strength, yield strength and elongation were $314 \mathrm{MPa}, 238 \mathrm{MPa}$ and $14 \%$, respectively. However, in the as-cast AZ80 alloy, the ultimate tensile strength, yield strength and elongation were $241 \mathrm{MPa}, 135 \mathrm{MPa}$ and $9 \%$, respectively. Fig. 14 shows that the mechanical properties of the
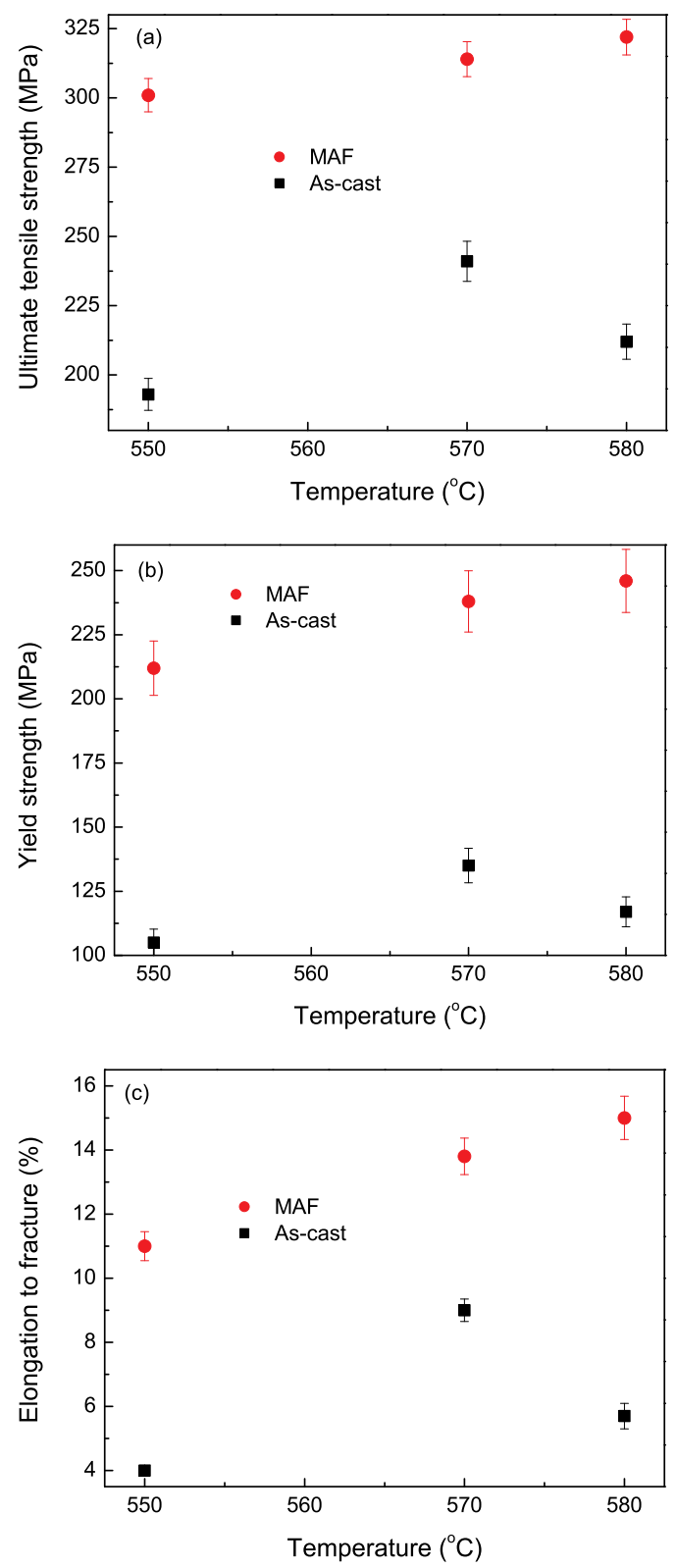

Fig. 14 Tensile mechanical properties of the thixoextruded as-cast alloy and MAF alloy plotted as a function of different isothermal temperature: (a) ultimate tensile strength; (b) yield strength; (c) elongation

as-cast formed alloy and the MAF formed alloy after thixoextrusion at different isothermal temperatures for $5 \mathrm{~min}$. The tensile test results of MAF formed alloy presented slightly increase with isothermal temperature. For the as-cast alloy, the UTS, YS and elongation increased from $550{ }^{\circ} \mathrm{C}$ to $570{ }^{\circ} \mathrm{C}$. With further increasing the temperature from $570{ }^{\circ} \mathrm{C}$ to $580{ }^{\circ} \mathrm{C}$, the ultimate tensile strength, yield strength and elongation decreased from $241 \mathrm{MPa}, 135 \mathrm{MPa}$ and $9 \%$ to $212 \mathrm{MPa}, 117 \mathrm{MPa}$ and 6\%, respectively.

Fig. 15 shows that the microstructure of ascast and MAF formed AZ80 magnesium alloys after thixoextrusion at $570{ }^{\circ} \mathrm{C}$ for $5 \mathrm{~min}$. According to the 


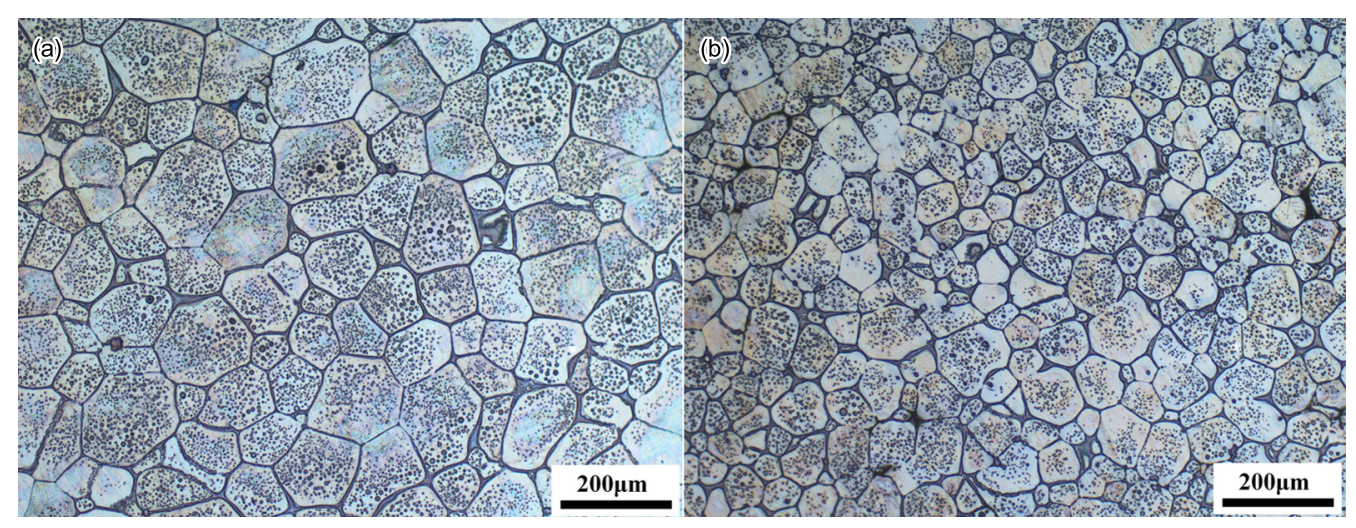

Fig. 15 Microstructures of the as-cast (a) and MAF formed AZ80 magnesium alloys (b) after thixoextrusion at $570{ }^{\circ} \mathrm{C}$ for $5 \mathrm{~min}$

Hall-Petch equation: $\sigma_{\mathrm{y}}=\sigma_{0}+K_{\mathrm{y}} d^{-1 / 2}$, where $\sigma_{\mathrm{y}}$ is the yield strength, $\sigma_{0}$ and $K_{\mathrm{y}}$ are material constants, and $d$ is the mean grain size. The value of $K_{\mathrm{y}}$, which is mainly dependent on the numbers of slip systems, is higher for the metals with hexagonal close-packed structure (HCP) than those with body-centered cubic (BCC) or face-centered cubic (FCC) structures. Note that magnesium alloys with HCP structure, the grain size had a significant influence on the yield strength. As shown in Fig. 15, the grain size of the as-cast AZ80 magnesium alloys treated by thixoextrusion was larger than that of MAF formed AZ80 magnesium alloys treated by thixoextrusion. Before thixoextrusion, the as-cast alloy was subjected to MAF. Therefore, fine and equiaxed grains were obtained due to recrystallisation ${ }^{[40-43]}$. At the same time, compared with the as-cast alloy, the MAF formed alloys were free from porosity, and had a uniform microstructure. After partial remelting, fine and spheroidal solid grains originated from fine and recrystallised grains ${ }^{[4]}$. In this work, the solid grain size of the ascast alloys after thixoextrusion was $87 \mu \mathrm{m}$. However, the solid grain size of the MAF formed alloys after thixoextrusion was $54 \mu \mathrm{m}$. As expected, better mechanical properties were obtained in the components thixoextruded from the starting material treated by MAF. Compared to the as-cast alloy of shape factor of 0.76 , the MAF formed alloy of shape factor reached 0.87 . The good degree of spheroidization in the MAF alloy after partial remelting was helpful for thixoformability.

\section{Conclusions}

(1) The new process, which was combinated threepass multi-axial forging and partial remelting, produced ideal, fine semi-solid microstructure, in which completely spheroidal primary solid grains had a little amount of entrapped liquid. However, in the as-cast alloy, inhomogeneous and coarse solid grains suspended in the liquid matrix after partial remelt- ing. Compared with the as-cast alloys, the degree of spheroidization was remarkably improved in the MAF formed alloys.

(2) The tensile mechanical properties of the components thixoextruded from the starting materials produced by MAF showed a significant advantage over those of the components thixoextruded from the starting materials produced by casting. The best mechanical properties were obtained for the thixoextruded MAF alloy at $580{ }^{\circ} \mathrm{C}$ for $5 \mathrm{~min}$ isothermal holding, with a ultimate tensile strength of $322 \mathrm{MPa}$ and a yield strength of $246 \mathrm{MPa}$ and a elongation of $15 \%$. The best mechanical properties were obtained for the thixoextruded as-cast alloy at $570{ }^{\circ} \mathrm{C}$ for $5 \mathrm{~min}$ isothermal holding, with a ultimate tensile strength of $241 \mathrm{MPa}$ and a yield strength of $135 \mathrm{MPa}$ and a elongation of $9 \%$.

\section{Acknowledgements}

This work was supported by Department of Education of Heilongjiang Province (No. 12511069), Heilongjiang Province Natural Science Foundation (No. QC2010110), Special Fund Project for Scientific and Technological Innovation Talents of Harbin (No. 2012RFQXS113) and Entrepreneurship for Under-graduates (No. 201210214008).

\section{REFERENCES}

[1] S.J. Luo, Q. Chen and Z.D. Zhao, Mater. Sci. Eng. A 50 (2009) 146.

[2] Q. Chen, Z.W. Huang, Z.D. Zhao and C.K. Hu, Compos. Mater. Sci. 67 (2013) 196.

[3] B.G. Yuan, C.F. Li, H.P. Yu and D.L. Sun, Trans. Nonferrous Met. Soc. China 19 (2009) s423.

[4] Z.D. Zhao, Q. Chen, F. Kang and D.Y. Shu, J. Alloys Compd. 482 (2009) 455.

[5] Y. Hu, B.L. He and H. Yan, Trans. Nonferrous Met. Soc. China S3 (2010) s883.

[6] B.G. Yuan, C.F. Li, H.P. Yu and D.L. Sun, Mater. Sci. Eng. A 527 (2010) 4185.

[7] Z.D. Zhao, Q. Chen, Y.B. Wang and D.Y. Shu, Mater. Sci. Eng. A 515 (2009) 152. 
[8] Y. Birol, J. Alloys Compd. 461 (2008) 132.

[9] Q. Chen, Z.X. Zhao, D.Y. Shu and Z.D. Zhao, Mater. Sci. Eng. A 528 (2011) 3930.

[10] H.V. Atkinson, Prog. Mater. Sci. 50(3) (2005) 346.

[11] Z.D. Zhao, Q. Chen, Z.J. Tang and C.K. Hu, J. Alloys Compd. 497 (2010) 402.

[12] Q. Chen, B.G. Yuan, G.Z. Zhao, D.Y. Shu, C.K. Hu, Z.D. Zhao and Z.X. Zhao, Mater. Sci. Eng. A 537 (2012) 25.

[13] G.H. Su, Z.Y. Cao, Y.B. Liu, Y.H. Wang, L. Zhang and L.R. Cheng, Trans. Nonferrous Met. Soc. China S2 (2010) S402.

[14] S.J. Luo, Q. Chen and Z.D. Zhao, J. Alloys Compd. 477 (2009) 602.

[15] Q. Chen, Z.D. Zhao, Z.X. Zhao, C.K. Hu and D.Y. Shu, J. Alloys Compd. 509 (2011) 7303.

[16] Z.D. Zhao, Q. Chen, H.Y. Chao and S.H. Huang, Mater. Des. 31 (2010) 1906.

[17] L. Zhang, Z.Y. Cao and Y.B. Liu, Trans. Nonferrous Met. Soc. China 20 (2010) 1244.

[18] X.M. Feng and T.T. Ai, Trans. Nonferrous Met. Soc. China 19 (2009) 293.

[19] L. Geng, H.W. Zhang, H.Z. Li, L.N. Guan and L.J. Huang, Trans. Nonferrous Met. Soc. China 10 (2010) 1851.

[20] Q. Chen, D.Y. Shu, C.K. Hu, Z.D. Zhao and B.G. Yuan, Mater. Sci. Eng. A 541 (2012) 98.

[21] G.H. Su, Z.Y. Cao, Y.B. Liu, Y.H. Wang, L. Zhang and L.R. Cheng, Trans. Nonferrous Met. Soc. China 20 (2010) S402.

[22] Z.D. Zhao, Q. Chen, S.H. Huang, F. Kang and Y.B. Wang, Trans. Nonferrous Met. Soc. China 20 (2010) 1630 .

[23] X.H. Du and E.L. Zhang, Mater. Lett. 61 (2007) 2333.

[24] M.J. Nayyeri and F. Khomamizadeh, J. Alloys Compd. 509 (2011) 1567.

[25] Q. Chen, S.J. Luo and Z.D. Zhao, J. Alloys Compd. 477 (2009) 726.
[26] Z.D. Zhao, Q. Chen, Z.J. Tang, Y.B. Wang and H.Q. Ning, J. Mater. Sci. 45 (2010) 3419.

[27] Y.S. Cheng, Q. Chen, Z.Q. Huang and S.H. Huang, Trans. Nonferrous Met. Soc. China 20 (2010) S739.

[28] M.Y. Zheng, K. Wu, M. Liang, S. Kamado and Y. Kojima, Mater. Sci. Eng. A 372 (2004) 66.

[29] Z.D. Zhao, Q. Chen, C.K. Hu, S.H. Huang and Y.Q. Wang, J. Alloys Compd. 485 (2009) 627.

[30] F. Czerwinski, Scr. Mater. 48 (2003) 327.

[31] Q. Chen, D.Y. Shu, Z.D. Zhao, Z.X. Zhao, Y.B. Wang and B.G. Yuan, Mater. Des. 40 (2012) 488.

[32] Z.D. Zhao, Q. Chen, Y.B. Wang and D.Y. Shu, Trans. Nonferrous Met. Soc. China 19 (2009) 535.

[33] J.G. Wang, P. Lu, H.Y. Wang, J.F. Liu and Q.C. Jiang, J. Alloys Compd. 395 (2005) 108.

[34] Z.D. Zhao, Q. Chen, C.K. Hu and D.Y. Shu, Mater. Des. 30 (2009) 4557.

[35] Z.D. Zhao, Q. Chen, Y.B. Wang and D.Y. Shu, Mater. Sci. Eng. A 506 (2009) 8.

[36] H.V. Atkinson and D. Liu, Mater. Sci. Eng. A 496 (2008) 439

[37] Z.D. Zhao, Y.S. Cheng, Q. Chen, Y.B. Wang and D.Y. Shu, Trans. Nonferrous Met. Soc. China 20 (2010) 178.

[38] R.G. Guan, Z.Y. Zhao, X.P. Sun, H.Q. Huang, C.G. Dai and Q.S. Zhang, Trans. Nonferrous Met. Soc. China 20 (2010) 729.

[39] Q. Chen, J. Lin, D.Y. Shu, C.K. Hu, Z.D. Zhao, F. Kang, S.H. Huang and B.G. Yuan, Mater. Sci. Eng. A 554 (2012) 129.

[40] Z.D. Zhao, Q. Chen, H.Y. Chao, C.K. Hu and S.H. Huang, Mater. Des. 32 (2011) 575.

[41] E. Tzimas and A. Zavaliangos, Mater. Sci. Eng. A 289 (2000) 228.

[42] R.G. Guan, J.L. Wen, X.H. Liu and X.Y. Meng, Rare Met. 21 (2002) 27.

[43] Z.D. Zhao, Q. Chen, L. Yang, D.Y. Shu and Z.X. Zhao, Trans. Nonferrous Met. Soc. China 21 (2011) 265.

[44] S.R. Yu, D.C. Li and N. Kim, Mater. Sci. Eng. A 420 (2006) 165. 